\title{
Sobre "peineta" e "cuero": entrevista com Oscar Guasch
}

\author{
Antônio Cristian Saraiva Paiva \\ Universidade Federal do Ceará, Fortaleza, CE, Brasil \\ Elias Ferreira Veras \\ Universidade Federal de Santa Catarina, Florianópolis, SC, \\ Brasil
}

\begin{abstract}
Oscar Guasch é professor titular do Departamento de Sociologia da Universidad de Barcelona. Sua obra representa um marco teórico na constituição do campo de estudos sobre sociologia da sexualidade na Espanha, no final dos anos 1980. Sua trilogia da homossexualidade, constituída pelos livros La sociedad rosa (Barcelona: Editorial Anagrama, 1991), La crisis de la heterosexualidad (Barcelona, Editorial Laertes, 2000) e Héroes, científicos, heterosexuales y gays: los varones en perspectiva de género (Barcelona: Ediciones Bellaterra, 2006), uma contribuição original para a reflexão sobre masculinidades e homossexualidades. Em 06 de junho de 2014, foi realizada entrevista com ele na Universidad de Barcelona, em Barcelona. Infelizmente ainda pouco conhecido no Brasil, seu trabalho dialoga com as epistemologias hegemônicas no estudo sobre gênero e sexualidade, constituindo-se, em muitos aspectos, como uma alternativa teórica original e fecunda. Na presente entrevista, Oscar narra sobre sua formação intelectual, sobre o cenário da sociologia e da antropologia da sexualidade na academia espanhola, apontando deslocamentos de gerações, objetos e teorizações. Reflete sobre mudanças nas políticas
\end{abstract}


sexuais em curso no movimento LGBT na Espanha, discorrendo sobre democracia e cidadania gay. Reivindicando um método de trabalho artesanal, divertido, e, ao mesmo tempo, crítico, na sua abordagem dos temas corpo, sexualidade, saúde e identidades de gênero Oscar sintetiza, no diálogo que se segue, as ideias fundamentais da trilogia da homossexualidade, de sua crítica às teorizações da masculinidade e, ainda, questiona a teoria queer.

Oscar Guasch também publicou outros livros: Sociología de la sexualidade (Barcelona: Centro de Investigationes Sociológicas, 2003), Sexualidades: diversidad y control social (Barcelona: Ediciones Bellaterra, 2003), Observacion participante (Barcelona: Centro de Investigaciones Sociologicas, 2002), Vida de hombres: relatos de vida (Ed.). (Barcelona: Ediciones Bellaterra, 2012).

184 Estudos Feministas, Florianópolis, 24(1): 183-198, janeiro-abril/2016 
1 O livro La sociedad rosa, de Guasch, aborda esse momento de emergência e institucionalização do movimento gay na Espanha, especialmente, o capítulo "El modelo gay".
21985.
Antônio Cristian Saraiva Paiva e Elias Ferreira Veras: Você afirma, no início de La sociedad rosa, que a "simpatia pelos perdedores" (p. 17) está na origem de sua vocação sociológica, e de seu trabalho sobre a homossexualidade. Você poderia relatar como foi sua formação intelectual? Poderia traçar o cenário de sua época de estudante, onde estudou, influências marcantes, predileções? Enfim, como se construiu a trajetória de Oscar Guasch?

Guasch: Estudei em Tarragona (Espanha) na década de 1980. Tarragona é uma cidade que está a $100 \mathrm{~km}$ de distância de Barcelona. Naquela cidade, na época, havia um dos departamentos de Antropologia Social mais inovador de toda Europa, inclusive, do mundo. A antropologia espanhola é uma antropologia sem colonialismo, ou seja, diferente das antropologias hegemônicas, como a britânica, a francesa ou a norte-americana que, com alguma exceção, eram potências coloniais que enviavam os antropólogos para entender os povos colonizados. A Espanha nunca teve um império colonial. Ora, a Espanha teve um império colonial no século XVI, mas, logo, o perdeu no século XVIII, XIX. Desse modo, quando se funda a antropologia, no século XIX, e princípios do XX, na Espanha, se questionava: "O que vamos estudar, uma vez que não temos "primitivos" nas colônias e que não temos colônias? O que faremos?". A solução foi estudar a nós mesmos. Bem, isso a partir do século XX, dos anos de 1970, quando as ciências sociais, a sociologia, a antropologia, depois do franquismo, depois da ditadura, voltaram a emergir.

Minha formação intelectual, portanto, se deu nesse contexto, no qual a antropologia começava a estudar os nativos, que eram nós mesmos. Enquanto a antropologia dizia que, para realizar as pesquisas, era necessária uma distância geográfica ou cultural, meus professores afirmavam que essa distância poderia ser construída de maneira crítica. Diante da inexistência de colônias, poderíamos estudar a nós mesmos, porém, de maneira crítica. Tal perspectiva influenciou o meu olhar crítico a respeito do movimento gay, que, na Espanha, nasceu por volta de 1975 .

Quando comecei a estudar a homossexualidade na Espanha, nos anos de 1980, pós-franquismo, estudei os homossexuais, os gays - atualmente sabemos que o importante não é estudar os homossexuais, mas a homofobia; não é estudar os negros, mas o racismo - de maneira crítica. Acredito que todo poder e toda realidade merecem ser criticados. As vítimas, inclusive, merecem ser criticadas. É verdade que afirmo sentir admiração pelos perdedores, porém, se retomarmos Michel Foucault $^{2}$ e sua afirmação de que o poder é fluido, estar em todas as partes, nos damos conta de que as vítimas também possuem poder, ainda que seja pouco e pequeno. Esse poder também necessita ser criticado.

Estudos Feministas, Florianópolis, 24(1): 183-198, janeiro-abril/2016 185 


\begin{abstract}
${ }^{3}$ Michael Pollak (1948-1992), sociólogo e historiador de origem austríaca, radicou-se na França a partir de 1971, tendo sido orientado por Pierre Bourdieu. Escreveu artigos em Actes de la Recherche en Sicences Sociales e deixou um inestimável legado na reflexão sobre memória, testemunho $e$ gestão da identidade social em situações-limite. Destacam-se, nesse sentido, os livros L'expérience concentracionnaire: essai sur le maintien de l'identité sociale (Paris: Métailié, 1990) e Une identité blessée (Paris: Métailié, 1995), sobre os campos de concentração, e Vienne 1990 (Paris: Gallimard, 1992). No que conceme à questão gay, publicou textos fundamentais, tais como L'Homosexualité masculine: le bonheur dans le ghetto? (1984) e Os homossexuais e a AIDS: sociologia de uma epidemia (São Paulo: Estação Liberdade, 1990), dentre outros.
\end{abstract}

${ }^{4}$ Referência ao diretor de cinema Pedro Almodóvar, reconhecido internacionalmente por seus filmes, que abordam o universo gay e travesti espanhol.
Pessoalmente, tenho certa distância crítica em relação ao movimento gay na Espanha. Certamente apoio as reivindicações desse movimento (combate à lesbofobia, transfobia, homofobia). Todavia, isso não significa que não se pode fazer uma análise crítica dessa realidade. Essa visão crítica a respeito do movimento LGBT é legítima para a análise de outras minorias sociais, sejam elas étnicas, raciais, etc.

Os professores de Tarragona também estudavam a si mesmos. Meu diretor de tese, por exemplo, que era psiquiatra, estudou o manicômio em que estava trabalhando; outro professor, que fumava maconha, realizou uma pesquisa em antropologia cultural sobre a subcultura do hachís em Barcelona; um professor imigrante - na Catalunha somos um povo de destino de imigração espanhola - fez uma pesquisa sobre os imigrantes; um outro, que era coroinha, fez um estudo sobre religiosidade popular. Contudo, quem mais me influenciou foi, provavelmente, Michael Pollak, ${ }^{3}$ pessoa fantástica, muito cuidadoso e amável comigo, com quem aprendi muito. Por intermédio de Michael Pollak, assumi toda a herança foucaultiana.

Essas seriam as minhas influências: a antropologia social, a sociologia qualitativa; e, como autores, Foucault através de Pollak, que tinha uma leitura, eu diria, divertida e simpática de Foucault.

A. P. @ E. V.: E na Universidade, as grandes teorizações da sociologia, da antropologia, tais como o funcionalismo, o estruturalismo...

Guasch: Nos anos de 1980, no princípio dos anos de 1990, quando realizava meu doutorado em Tarragona, entre 1987 e 1991, vinham professores norte-americanos da Universidade de Berkeley (Califórnia) e nós ríamos, pensando: "Mas isto é muito antigo". Nós, estudantes de um povoado periférico, como era a Espanha naquele momento, tínhamos essa impressão. Também em relação aos franceses que vinham para cá, e dizíamos: "A antropologia que fazem os franceses é muito antiga". Qual era a particularidade da Espanha? Durante a ditadura franquista, as grandes tradições sociológicas, antropológicas, inclusive, históricas, foram rompidas. Ou seja, houve a guerra civil, a ditadura franquista; os pensamentos teóricos que chegam de outras partes do mundo chegam, mas...

Na Espanha estava tudo por fazer. Consequentemente, não tive muitas influências teóricas, não porque não as conhecíamos, mas porque não existiam cátedras ou pessoas que pudessem impor uma influência intelectual. Era um pouco como os filmes de Almodóvar. ${ }^{4}$ Era tudo provisório, imaginativo, muito artesanal. Atualmente, o pensamento antropológico e sociológico está institucionalizado na Academia, porém, antes, íamos à Universidade com chinelas e éramos felizes. 
${ }^{5}$ Erving Goffman (1922-1982), sociólogo canadense, professor de sociologia da Universidade da Califórnia, associado à segunda geração da conhecida Escola de Chicago. Seu trabalho consiste numa profunda exploração sociológica sobre encontros e interações sociais, discutindo questões sobre apresentação e controle de informação pessoal, aceitação, estigma e estratégias de interação. As recentes traduções para o português de suas obras ampliam o acesso à reflexão sociológica do autor: Comportamento em lugares públicos (Petrópolis: Vozes, 2010) Ritual de interação (Petrópolis: Vozes, 2011), Os quadros da experiência social (Petrópolis: Vozes, 2012). Outros títulos, traduzidos nos anos 1970-1980 no Brasil são: A representação do eu na vida cotidiana (Petrópolis: Vozes, 1975), Estigma (Rio de Janeiro: Guanabara, 1981) e Manicômios, conventos e prisões (São Paulo: Perspectiva, 1974). ${ }^{6} \mathrm{GUASCH}, 1987$.

7 Utilizado, por exemplo, nos penteados das mulheres que dançam flamenco.

${ }^{8}$ Também no Brasil a categoria de "entendido" foi amplamente acionada por homossexuais de classe média, nas metrópole brasileiras, a partir do final dos anos 1960 , como sistema de classificação sexual permeado de uma ideologia "igualitária", contrastando com um modelo hierárquico, mais associado às classes populares. Cf.: GUIMARÃES, 2004 FRY, 1982; GREEN, 2000

${ }^{9} \mathrm{GUASCH}, 1991$

${ }^{10}$ Os livros La sociedad rosa e La crisis de la heterosexualidad resumem o material apresentado na tese de doutorado de Guasch. 1 Nomeada por Teresa de Lauretis em The practice of love: lesbian sexuality and perverse desire (1994), a teoria queer, de origem norte-americana, abriga um conjunto de posições teóricas interdisciplinares associadas aos estudos gays e lésbicos, ao pósestruturalismo, ao pensamento pós-identitário e ao pós-
Posteriormente, fui influenciado pelo interacionismo estratégico de E. Goffman. ${ }^{5}$ Foucault e Goffman, basicamente. Enquanto Foucault possibilita pensar a estrutura histórica e ampliar a análise do contexto, Goffman possibilita pensar o micro, as relações.

A. P. e E. V.: E seu trabalho de conclusão da Graduação? Guasch: A tesina [monografia de conclusão de curso] se chamava De la peineta al cuero: los homossexuales na Catalunya actual, ${ }^{6}$ em que discuto, segundo as figuras do pente (peineta), ${ }^{7}$ associadas aos homossexuais afeminados, e do couro (cuero, leather), o processo de masculinização da homossexualidade, que aprendi com Pollak; e a tese de doutorado se intitulava El entendido. Antes da chegada da categoria gay dos EUA, na Espanha não perguntávamos se uma pessoa era homossexual. Por exemplo, não perguntávamos se um homem que passeava com sua esposa e filho era homossexual, mas se era entendido. ${ }^{8} \mathrm{O}$ fato de ter prática sexual com outro homem não condicionava sua identidade social ou pessoal. A mudança acontece depois, com a imposição da categoria gay. Antes, perguntávamos: "entendes? Sim ou não?".

A tese, então, se chama El entendido: condiciones de aparicón, dessarrolo y disolución de la subcultura gay en España. ${ }^{9} \mathrm{Na}$ Espanha, a subcultura gay teve valores específicos durante um período, mas logo se dissolveu na cultura maior, ou seja, na cultura hétero-capitalista-patriarcal. ${ }^{10}$

A. P. e E. V.: Seus trabalhos, especialmente, a trilogia da sexualidade (composta pelos livros La Sociedad, Heroes, La Heterosexualidad...) contribuiu para inaugurar, configurar o campo da Sociologia da Sexualidade na Espanha...

Guasch: Fui uma das pessoas que liderou o desenvolvimento da Sociologia da Sexualidade na Espanha, porém, não fui o único, mas, com Raquel Osborne Verdugo em Madrid; e, ainda, Jordi Roca Girona, em Tarragona. Foi um projeto coletivo, no entanto, não coordenado. Havia pessoas em Sevilha fazendo coisas... A vantagem que a Sociologia da Sexualidade ou a Antropologia da Sexualidade teve, na Espanha, foi que, ao ser um âmbito periférico dentro das Ciências Sociais, não existiram grandes poderes para dizer "Isto é meu!". Desse modo, cada um foi livre para fazer, inventar, escrever. Isso foi bonito. Todos se conheciam, mas cada pessoa fazia o que queria. A tradição foi essa. É verdade que, depois, nós, que estávamos na Academia, fomos legitimamente criticados pela teoria queer. ${ }^{11}$ Foi como se tivesse existido uma divisão entre os precursores: os antigos, os mais velhos, que estão na Universidade, e os jovens, teóricos queer, que não estavam na Universidade, a maioria não acadêmicos.

Estudos Feministas, Florianópolis, 24(1): 183-198, janeiro-abril/2016 187 
feminismo. Nomes importantes desse campo de crítica do sistema de sexo-gênero estáveis $e$ coerentes são: Eve K. Sedgwick Judith Butler, D. Halperin, R. Seidman, J. Halberstam, M. H. Bourcier, A. Green, dentre outros. No Brasil, a difusão da reflexão queer se dá a partir do início dos anos 2000 , com os trabalhos de R. Miskolci, G. Louro, B. Bento e L. Pelúcio.

${ }^{12}$ Em 1998 Ricardo Llamas inaugura, na Espanha, os debates a respeito da teoria queer, com o livro Teoria torcida, que combina pesquisa com uma revisão da construção do preconceito contra gays e lésbicas.

${ }^{13}$ A tese foi recentemente publicada em livro: ADIEGO, Jose Antonio Langarita. En tu árbol o en el mío: una aproximación etnográfica a la práctica del sexo anónimo entre hombres. Barcelona: Bellaterra, 2015

\footnotetext{
${ }^{14} \mathrm{~A}$ oposição essencialismo versus construtivismo social tem marcado, lembra-nos Heilborn, o debate teórico sobre corpo, gênero e sexualidade. O construtivismo insiste na crítica desnaturalizante e desessencializante desses objetos, apontando o papel constituidor de linguagens, práticas, significados e convenções culturais na experiência deles. Cf. HEILBORN, 1999; WEEKS, 1999 ; DUARTE, 2004.

${ }^{15}$ Presente, por exemplo, em Problemas de gênero: feminism e subversão da identidade (2003) e Bodies that matter: on the discursive limits of "sex" (1993).

16 Publicado no Brasil como $A$ construção social da realidade: tratado de sociologia do conhecimento (1978).
}

Essa discussão ocorreu a partir dos anos 2003, 2004, 2005, quando a teoria queer começa a ter uma importância na Espanha, sobretudo, liderada por Ricardo Llamas, ${ }^{12}$ um dos fundadores da teoria queer na Espanha. De um lado, estavam os que faziam antropologia, sociologia da sexualidade desde a Academia; do outro, os jovens - agora não tão jovens pessoas não acadêmicas, que trabalhavam em Institutos, que publicavam coisas queer - isso nos anos 2000 . Atualmente, os novos jovens, aqueles que têm 23, 24, 25 anos, criticam os queer, chamando-os antigos. Diria que há quatro gerações: a primeira corresponderia a Michel Pollak, na França, enquanto, na Espanha, estaria Alberto Cardín, professor que, como Pollak, também faleceu em consequências do vírus HIV. Cardín foi fundador da sociologia da sexualidade na Espanha; na segunda, estariam Raquel Osborne e eu; na terceira, Ricardo Llamas e os teóricos queer; finalmente, na quarta geração, estaria, por exemplo, José Antônio Langarita, jovem pesquisador, que realizou uma pesquisa sobre os usos gays-sexuais dos espaços públicos de Barcelona. ${ }^{13}$

A. P. e E. V.: O que você destacaria como importante no deslocamento de objetos, metodologias, conceitos nessas gerações?

Guasch: Existe uma linha argumental comum que se mantém. O eixo geracional se organiza em torno da necessidade de matar o pai ou a mãe. Quer dizer, não precisei matar Cárdin, porque o mesmo morreu antes. Todavia, os queer tiveram que matar a mim e a Osborne sob o argumento de que nós estávamos na Universidade, de que éramos muito acadêmicos. Contudo, existe uma linha intelectual comum que é o construtivismo. ${ }^{14}$

Acontece que os teóricos queer não reconhecem os teóricos do construtivismo. Critico os teóricos queer por repetirem coisas que foram inventadas por Simone de Beauvoir: "Não se nasce mulher: torna-se"; por E. Goffman, que já afirmava nos anos de 1960, que as relações sociais são teatro, atuações, ideia presente na teoria da performatividade de gênero de Judith Butler. ${ }^{15}$ Por que os queer não citam essas pessoas? Porém, apesar de não citarem, inclusive os queer são construtivistas, ainda que não se definam como tais. Não citam, por exemplo, Peter L. Berger e Thomas Luckmann, e seu livro La construcción social de la realidade, ${ }^{16}$ ainda que a teoria queer seja construtivista. Por que não se definem como construtivistas?

Penso que está tudo escrito. Acredito que os gregos escreveram tudo. Shakespeare, inclusive, é uma releitura dos gregos. O que é a teoria queer? É uma releitura do construtivismo. Não é uma novidade, na minha opinião. Por exemplo, o conceito de performatividade é uma releitura de Goffman. Porém, Judith Butler não o cita. Por que não o conhece? Por que o ignora? Não sei. 
A. P. e E. V.: Tal cenário não estaria relacionado com as mudanças das políticas sexuais, que, nos anos de 1980, teriam um enfoque mais identitário, enquanto, atualmente, se vive a esfera dos direitos, da cidadania? Tais mudanças se traduzem nas teorias.

Guasch: Claro. A teoria se ajusta ao contexto social. Podemos, por exemplo, estabelecer uma linha para pensar como os espaços gays evoluíram. Primeiro, a clandestinidade e o silêncio. Depois, foram criadas instituições (saunas, bares, etc.). Atualmente, a internet. Do ponto de vista teórico, existe uma correspondência. Como se chamava a homossexualidade quando estava proibida? Homossexualismo, que significava enfermidade e controle social. Em seguida, surge gay como categoria política de resistência. Hoje, as pessoas se chamam gays, porém, de um modo distinto. Do mesmo modo, como funcionavam as categorias identitárias? Homossexualismo: "Sou doente, sou doente"; Gay [resistência]: "Não sou doente. Liberação!"; Gay atual: "Quero me casar. Quero ter filhos". De algum modo, as teorias reproduzem essas transformações...

Primeiro, houve uma crítica à medicalização da homossexualidade e das "perversões sexuais"; depois, uma crítica aos instrumentos de controle social, por exemplo, as questões gays relacionadas ao mercado, ao culto ao corpo; atualmente, os gays e as lesbianas jovens estão, digamos, mais normalizados, vivem sua homossexualidade e sua lesbianidade de maneira mais relaxada, diferente de como eu vivi a minha. Acredito que os marcos teóricos se adequam a essas transformações. Exceto em contextos muito homofóbicos - como Polônia, Rússia, Irã, México, onde a identidade gay ainda é necessária para resistir, neste momento, na Espanha, na França - ainda que na França tenham acontecido muitos problemas - onde a Lei tem um efeito pedagógico, onde a Lei protege - essa identidade não parece ser tão necessária. Seguramente devemos combater a homofobia, como devemos combater o racismo. Mas já não estamos nos EUA dos anos de 1960 com Martin Luther King Jr. Estamos com Obama presidente. Certamente que devemos combater o racismo, porém Obama é presidente!

Portanto, creio que os marcos teóricos se ajustam ao longo da história, vão produzindo novos modelos para dar conta de novas realidades, como por exemplo, os novos modelos de família, o poliamor, e outras coisas que nem sequer imaginamos.

A. P. e E. V.: Quais seriam os desafios para a escrita de uma Sociologia/Antropologia da Sexualidade mais de duas décadas depois de La sociedad Rosa?

Guasch: Acredito que devemos escutar e observar como as novas gerações vivem sua sexualidade. Não apenas os homossexuais, as lésbicas ou os/as transexuais, mas também 
${ }^{17}$ FOUCAULT, 1999.

18 Ver o livro de Guasch Observacion participante (2002).

19 José Luis Rodríguez Zapatero, político do Partido Social Obrero de Español, foi presidente do governo da Espanha no período de 2004-2011, em dois mandatos consecutivos. os denominados heterossexuais. Na verdade, essas categorias já não servem. Vivenciamos um momento de mudança de paradigmas econômico, social e tecnológico.

O conceito de biopoder, ${ }^{17}$ como pensou Michel Foucault, deve, inclusive, ser repensado. Por exemplo, ao receber um transplante de fígado de porco, continuo sendo humano? Seria um humano-porco? Quando tiver uma mão biônica, quando injetarem um gene de mosca... Seguiremos vivendo o biopoder, contudo, este está mais sofisticado. O próprio conceito de humanidade está se transformando. Falamos, atualmente, que somos pós-humanos. Que vivemos em uma pós-democracia. Já não somos cidadãos. Neste momento, nossos direitos estão em função da nossa renda. Pós-democracia. Pós-humanos. Pósheterossexualidade. Estamos em outra parte. Nosso desafio é escrever para entender os novos erotismos e se questionar como são os erotismos nessa nova sociedade. Uma coisa são as novas tecnologias que te possibilitam, por exemplo, ter sexo em três minutos. No entanto, o que está por debaixo dessas novas práticas? Não sei.

Minha aproximação metodológica é muito artesanal. Está relacionada com a observação participante e com a experiência. ${ }^{18}$ Não tenho essa experiência do sexo rápido através de aplicativos telefônicos, por exemplo. Dessa forma, tentarei formar as novas gerações para que tenham instrumentos para construir suas experiências e comunicá-las à sociedade. Não posso fazer. Esta é uma tarefa das novas gerações.

A. P. e E. V.: Boa parte de seu esforço intelectual é de relacionar homossexualidade, masculinidade enquanto tecnologia de gênero. No livro Herois, científicos, heterosexuales y gays, por exemplo, você propõem figuras ideal - típicas de masculinidade, utilizando, inclusive, uma intrigante epígrafe/dedicatória: "a la testosterona". Seria uma espécie de "analítica da testosterona"? Guasch: Dedicar o livro à testosterona foi uma pequena vingança contra o feminismo de Estado na Espanha. O feminismo de Estado é a maneira como o Estado recorre a algumas das reivindicações do movimento feminista. Durante o governo Zapatero, ${ }^{19} \mathrm{O}$ feminismo teve bastante poder. $\mathrm{O}$ que não está mal. O que acontece é que era um feminismo um pouco estereotipado. Um tipo de feminismo que se preocupa muito com a violência de gênero contra as mulheres, mas que se preocupa pouco com a violência de gênero contra os/as transexuais, as lésbicas, os homossexuais; ou se preocupa pouco com a violência de gênero contra alguns homens que são heterossexuais, mas que são agredidos, insultados, injuriados porque não são considerados homem o bastante, que "não dão no couro". Estou com as mulheres feministas contra a violência de gênero. Porém, Ihes peço: Por favor, a violência de gênero afeta as mulheres, mas também afeta homossexuais, travestis, 
lésbicas e homens heterossexuais "barriga-branca". Então, a minha ideia de dedicar o livro se deve a esse contexto, como uma forma de dizer que há mais violência de gênero do que aquela de que "vocês" se ocupam.

Por que relacionar homossexualidade com masculinidade? Porque a homossexualidade, inclusive, ser gay, é uma forma de ser homem. Na minha opinião, não se pode entender a homossexualidade sem fazer uma análise da masculinidade. São duas caras da mesma moeda. Por um lado estão aqueles que são muito afeminados, mas que renegam a homossexualidade; de outro, aqueles que são heterossexuais, mas que mantêm relações com outros homens. No fundo, são os mesmos. A homossexualidade é uma forma médica de homofobia.

A. P. e E. V.: Por isso você afirma que deixou de ser gay? Guasch: Sim. Estamos em outra época. Ao contrário do que dizem os queer, sou uma pessoa bastante moderna [risos]. Adapto-me aos contextos. Se vivesse na Rússia, certamente assumiria uma identidade gay. Vivo, no entanto, na Espanha, em uma democracia. Devemos fazer um discurso crítico sobre a realidade gay, sobre o processo de mercantilização da realidade gay. Por exemplo, me dói muitíssimo o fato de saber que muitos jovens estão economizando dinheiro para comprar uma camiseta apertada Mulan. Não! Isso não é ser gay! Ser gay é ser livre. Mas que liberdade? Para fazer uma viagem em um cruzeiro gay? Não! Tem que ser livre em todas as partes. E não em um barco gay.

Neste momento, meu pacto é com os homens heterossexuais para combater a homofobia. Por exemplo, os homens heterossexuais não são conscientes de que sofrem homofobia. Existem dois tipos de homofobia. A homofobia simples, que afeta os homossexuais, e a homofobia complexa. O termo marica [viado], que na Espanha é uma injúria, se aplica aos homossexuais, mas, também, aos homens que "não dão no couro", aos homens mandados por uma mulher, aos homens que são covardes, aos meninos gordos da escola que não conseguem subir na corda [durante as aulas de Educação Física]... Marica!!! Qualquer homem que "não der no couro" é rebaixado a um status inferior igual ao das mulheres. Mulher e marica. Nesse status se encontram os homossexuais e os heterossexuais que não são considerados homem o bastante. Por isso, quero fazer um pacto político com esses homens heterossexuais para combater a homofobia. Além disso, muitos homossexuais apresentam uma homofobia interiorizada. Às vezes, a homofobia é sexy. A homofobia funciona como intercâmbio erótico. A imagem de um homem homofóbico (com cara de machão, de ríspido, de serial killer) desperta erotismo em outros homens. Ora, ainda que o erotismo seja livre, é necessário ter consciência disso. 
A. P. e E. V.: Poderíamos evocar, a esta altura, sua reflexão em torno dos conceitos de "resistências passivas" e de "heroicidade marica".

Guasch: Jesus Cristo é marica, mas, ao mesmo tempo, é um herói. O que faz o herói? Sacrifica-se e oferece sua vida aos demais. Este ato o legitima como herói. Contudo, é necessário morrer para legitimar-se? Ainda que Jesus Cristo seja uma resistência passiva, amorosa, sem violência, é um herói marica que acaba morrendo para salvar os outros. Pergunto-me se é necessário morrer para salvar os outros. Não podemos fazer uma resistência mais simples? Por que a morte? Não é melhor a vida? O sacrifício é necessário? Inventemos outra coisa.

A Catalunha é uma nação marica. Castilla ou Pais Vasco na Espanha são "homens de verdade". Nós catalãs somos maricas. Negociamos, falamos, discutimos... Um pouco de autocrítica irônica a respeito do nacionalismo catalão.

É ainda uma forma de ironizar a radicalização da masculinidade homossexual, o que considero muito estressante. Estou de acordo com Goffman quando este afirma que o gênero é performativo. Podemos performatizar a masculinidade de maneira erótica, sabendo, todavia, que se trata de uma atuação, de um teatro. Contudo, algumas pessoas acreditam que essa teatralização da masculinidade é real. Não! Isto é teatro. Temos que ser conscientes de que se trata de teatro. Se você gostar de erotizar essa performance masculina, tudo bem, mas não podemos acreditar que nossa identidade seja isso.

Há, ainda, uma terceira coisa a dizer sobre isso. Por exemplo, nas relações de bondage e sadomasoquismo quem tem o poder é o escravo. As pessoas que não entendem o sadomasoquismo pensam que o amo ou a ama tem o poder. Não! Quem manda é o escravo. Enquanto na relação entre homens e mulheres, geralmente, as mulheres utilizam um determinado tipo de estratégia sutil [de dominação] de que os homens não se dão conta. No caso da homossexualidade, "as passivas" (forma pela qual são ironicamente denominadas na Espanha) exercem um poder sobre os ativos. Certamente toda essa reflexão apresenta um componente irônico e sarcástico...

A. P. e E. V.: Qual sua proximidade com as teorias sobre masculinidade (por exemplo, Kimmel, Connell, Vale de Almeida, Halberstam, Preciado)?

${ }^{20}$ Michael Kimmel, sociólogo norte-americano, fundador da revista Men \& Masculinities, autor de diversos trabalhos sobre gênero e masculinidades. Cf. KIMMEL, 1998.

${ }^{21}$ Cf. SANTOS, 2010.

Guasch: Bebi de todos. O que mais me interessou foi Kimmel, ${ }^{20}$ por pensar o gênero e a raça a partir do ponto de vista da experiência. Quando afirma que os brancos não têm consciência de raça; que os homens não têm consciência de gênero; acrescentaria que os heterossexuais não têm consciência de orientação sexual. Boaventura de Sousa Santos ${ }^{21}$ explica que todo ato de conhecimento é um ato de autoconhecimento. Tal afirmação se conecta com as reflexões de Kimmel. Sem a experiência da raça, 
22 Criada por Robert McRuer (2006), a teoria crip condensa reflexões sobre sexualidade trabalhadas pela teoria queer, e sobre questões envolvendo a deficiência, a partir dos disability studies, problematizando a distinção natural entre corpos considerados normais (abled bodies) e corpos considerados deficientes (disabled bodies). Cf. MCRUER, 2006

${ }^{23}$ Guasch utiliza aqui a topologia norte-sul tal qual trabalhada por Santos (2010). do gênero e da orientação sexual este autoconhecimento não é possível. Por isso os heterossexuais dizem: O que querem os homossexuais na Espanha se já têm tudo? Discotecas gays, muitas relações sexuais, são bonitos, a Lei os protege, etc.? Ou dizem sobre as mulheres: Que querem as mulheres, se elas já têm tudo? Nos EUA se diz dos negros: O que querem os negros, se já têm vagas reservadas na universidade, na Polícia, etc.? Aqueles que fazem esse tipo de questionamento não têm a experiência identitária, ou seja, o ato de conhecimento não passou pelo ato de autoconhecimento.

A. P. e E. V.: O que você acha dos trabalhos de Beatriz Preciado, sobre suas experimentações com a testosterona, e de J. Halberstam sobre as masculinidades femininas?

Guasch: É uma possibilidade. Antes funcionávamos com categorias dicotômicas e opostas, contudo, o paradigma está mudando. O que significa essa mudança de paradigma? Neste momento, a teoria da relatividade e da física quântica, por exemplo, nos dizem que um fóton pode estar ao mesmo tempo em dois lugares. Isto, aplicado às ciências sociais, o que significa? No que falávamos, masculinidade e feminilidade (feminidad) já não são dois corpos opostos. Masculino e feminino podem integrar-se e podem conviver.

Quanto a Preciado, da mesma maneira que Goffman fala que as relações sociais são interações teatrais ou que Butler fala da teoria da performatividade, creio que, neste teatro [em que vivemos todos], existem atores que estão atuando. Creio que este seja um termo que posso aplicar a Preciado: atuação.

A. P. e E. V.: A teoria queer traria alguma novidade? Guasch: No âmbito da sexualidade não! Contudo, a teoria queer influenciou outros âmbitos, como a releitura do corpo, por exemplo, com a teoria crip, ${ }^{22}$ das pessoas que têm algum tipo de diversidade funcional, assimétricas, com amputações. A teoria queer teve uma poderosa influência - não se trata de novidade - na releitura sobre os corpos sociais estigmatizados. Não tanto em questões de sexualidade, mas isso é uma ideia pessoal. Mas essas influências da teoria queer creio que mudam de acordo com os países.

A. P. e E. V.: A teoria travesti seria uma alternativa à teoria queer?

Guasch: Creio que a teoria social tem que ser divertida, tem que se encarnar na realidade. A teoria queer é um invento anglosaxônico. Novamente, os países do Sul - a Espanha é meio sul, meio norte - buscam no norte coisas que já sabemos. ${ }^{23} \mathrm{Em} 1973$, 1974, sobretudo, nos anos posteriores à morte de Franco, viveuse na Espanha uma explosão de liberdade. Período chamado pelos antropólogos de "período liminar". O velho estava morto,

Estudos Feministas, Florianópolis, 24(1): 183-198, janeiro-abril/2016 193 
no entanto, o novo ainda não tinha nascido. Nesse intervalo houve um período de liberdade fabuloso. Nesse contexto, por exemplo, nas Ramblas de Barcelona havia travestis (mal) hormonizadas muito livres. Chamo a teoria queer de teoria travesti porque entendo que a experiência dessas mulheres/travestis foi revolucionária. Para mim, a teoria queer é algo intelectual e acadêmico. Enquanto a experiência real dessas mulheres-trans, de qualquer travesti, em qualquer parte do mundo, é a teoria queer real, pois se baseia em sua experiência, em sua vida cotidiana. Prefiro, mas isso é uma interpretação minha, muito passional, chamar a teoria queer de teoria travesti. Travestis com peitos, com lábios de silicone... Parece-me mais revolucionário e mais subversivo.

A. P. e E. V.: Qual foi recepção de Foucault na Espanha? Guasch: Foucault não demorou a chegar à Espanha. Na verdade, chegou primeiramente à Catalunha. Na Espanha, até os anos de 1970 e 1980, as pessoas falavam, sobretudo, francês. Somos basicamente francófonos. Pois, para nós, a França era a Europa. Para os espanhóis, tudo estava na França: a liberdade, a democracia, a república, os intelectuais... Nesse sentido, Foucault rapidamente chegou à Espanha, pois todos liam francês, enquanto, por exemplo, nos EUA, chegou tarde, uma vez que as traduções foram feitas tardiamente. Diria, inclusive, que a teoria queer é uma releitura tardia de Michel Foucault aplicada ao caso norte-americano.

Ora, os estudos gays e o movimento feminista nos EUA, inclusive os movimentos pelos direitos civis dos negros, criaram, nos anos 70-80 um marco identitário para combater a opressão. Ou seja, negros, gays, lésbicas afirmavam uma identidade muito definida. O que faz a teoria queer nesse contexto? Afirma que se pode ser negro de muitas maneiras. Pode-se ser lésbica de muitas maneiras. Pode-se ser homossexual de muitas maneiras. Porém, já sabíamos disso na Europa. Eram os americanos que tinham um problema de identidade claustrofóbica. Na Espanha, não! As travestis sabiam que podiam ser travestis de muitas maneiras. Na Espanha, por exemplo, a pergunta era: Entendes? Não era uma pergunta identitária, tipo: És homossexual? És lésbica? Não. Contudo, as discussões teóricas experimentais dos países periféricos não chegam aos países do Norte. Um dos desafios que temos é recuperar e manter nossas próprias visões da realidade. Vivendo num país meio periférico, meio central, não necessitamos das teorias importadas, temos nossos próprios marcos teóricos... Boaventura de Sousa Santos, Alberto Cardin, Michel Foucault... Não necessitamos de Judith Butler.

A. P. e E. V.: Isso teria a ver com a análise dos modelos de homossexualidade que você elabora em Sociedad Rosa: o "modelo pré-gay", baseado na identificação da homossexua-

194 Estudos Feministas, Florianópolis, 24(1): 183-198, janeiro-abril/2016 
lidade masculina com o feminino versus o "modelo gay"? Guasch: Sim. Vejamos o caso da Polônia, onde aconteceu algo parecido. Qual era a situação dos homossexuais, lésbicas, transexuais na Polônia comunista, aquela que não estava dentro da União Europeia? Uma sociedade onde havia o modelo prégay. A Igreja Católica polonesa era muito homofóbica, a sociedade polonesa era muito homofóbica. O que aconteceu quando a Polônia se democratizou e se incorporou à União Europeia? Todos os imaginários democráticos para pensar a homossexualidade chegam à Polônia: falamos, aqui, do modelo gay dos EUA, com certa masculinização da homossexualidade, criação de instituições como bares, saunas, discotecas, etc., o que, no regime comunista ou pré-democrático, não era possível, pois havia repressão. Inclusive, quando chegou a democracia na Polônia, havia um controle social de uma lgreja Católica e uma sociedade extremamente homofóbicas. Havia, na Polônia, como aconteceu com a Espanha, um modelo prégay de resolver as questões relacionadas à homossexualidade, ou seja, na clandestinidade, no silêncio. Isso também se passou na Espanha, com o fim da ditadura franquista e a chegada da democracia.

A. P. e E. V.: Na França, observa-se, atualmente, certo temor, uma espécie de pânico social em relação à "teoria do gênero", por exemplo, com o medo da repercussão dessa teoria na educação das crianças. Masculino e feminino começam a ficar não tão claros e distintos... O que, em alguns casos desperta um desejo de retomada de modelos essencializantes sobre o gênero, a sexualidade. Como você avalia esse contexto?

Guasch: O que acontece é que a sociedade francesa é muito conservadora. Se analisarmos a sociedade francesa na longa duração, perceberemos que ela é profundamente conservadora. Fizeram uma revolução, decapitaram o Rei, porém existe uma série de correntes subterrâneas conservadoras. Por exemplo, todos se surpreendem com o fato de a República Francesa ser contra o matrimônio gay, com manifestações massivas de jovens contra o matrimônio gay. Ora, a França sempre foi um estado conservador. Na Espanha, se passa o contrário. Governada pelo Partido Popular, um partido conservador, a sociedade espanhola, subterraneamente, tem uma importante tradição anarquista, como a Rússia. Ou seja, os movimentos anarquistas na Catalunha e na Andaluzia foram muito potentes. Com a guerra civil e a ditadura de Franco, muitos daqueles que faziam parte desses movimentos foram mortos. Porém, essa tradição de conhecimento tácito que diz: com teu cu, faça o que quiser, permaneceu. Essa tradição anarquista subterrânea explica o fato de a Espanha ser uma das sociedades mais tolerantes e respeitosas com os gays, lésbicas e transexuais. O problema da França é identitário, na medida em que projeta uma imagem 
que não corresponde à sua identidade. Liberdade, igualdade, fraternidade... mas os franceses são muito conservadores.

Neste momento, existem dois controles de qualidade democrática nas sociedades. Um referente aos direitos das mulheres. Outro, referente aos direitos dos homossexuais. O que nos indica que a Rússia não é uma sociedade democrática? Não se respeita os direitos dos homossexuais; o que nos indica que o Irã não é uma sociedade democrática? Não se respeita o direito das mulheres. O que permite o selo de qualidade de uma sociedade democrática é o respeito pelas minorias, pelos grupos subalternos, que, nesse momento, ao menos nas sociedades ocidentais, são as minorias étnico-raciais, os homossexuais e as mulheres. Minha opinião é que, enquanto existir democracia na Europa, os direitos de gays, lésbicas e transexuais estarão protegidos.

A. P. e E. V.: Como, em sua trajetória, se articula essa tensão entre experiência pessoal e escolhas teóricas? Retomamos uma frase sua: "Escribir sobre relaciones interpersonales y sobre sexo tiene sus inconvenientes" (p. 18-19). Um dos inconvenientes consistiria em defrontar a dúvida que espreita a subjetividade do pesquisador que pesquisa sobre gays: "se estuda gay é porque é gay" (espécie de "totalitarismo moral", como você afirma em La crisis de la heterosexualidad, p. 29).

Guasch: Na medida em que todo ato de conhecimento é um ato de autoconhecimento, acredito que conhecer o próprio grupo de pertencimento é autoconhecimento. Porém, tal conhecimento necessita ser crítico. Sendo negro, devo realizar uma análise crítica da negritude. Não posso reproduzir os estereótipos existentes sobre a negritude; sendo uma mulher, não posso definir as mulheres apenas como vítimas, mas propor um discurso crítico sobre as mulheres; do mesmo modo, como gay, homossexual devo fazer um discurso crítico sobre a homossexualidade. Não somos apenas vítimas. Devemos combater a homofobia? Sim. Ao longo da história os homossexuais, as lésbicas e as transexuais foram perseguidas, maltratadas, assassinadas, torturadas? Sim. Porém, não somos perfeitos. Necessitamos ser criticados para melhorar, para crescer.

A. P. e E. V.: O que você pensa sobre o movimento LGBT? O que implica sua insurgência em relação à institucionalização da homossexualidade?

Guasch: A teoria social ensina que os grupos periféricos, marginais, subalternos carregam consigo a semente da transformação social. Quem inventou as novas formas de relações matrimoniais heterossexuais? Os gays. Ao proporem, por exemplo, as relações sexuais abertas, negociadas. Isto foi agora exportado ao conjunto da sociedade. 
Atualmente, homens e mulheres heterossexuais negociam relações abertas. Todavia, acredito que, neste momento, a homossexualidade masculina está institucionalizada. Já não trazemos contribuições relevantes. Acredito que fomos integrados ao sistema e que nos "heterossexualizamos". As lésbicas estão em processo, enquanto as trans, ainda não sabemos. Nós, homens gays, já somos sistema. Não trazemos mais novidades; as novidades já foram assumidas pelo sistema.

Quanto ao movimento LGBT, na Espanha, tenho pouco contato. E, nesses momentos, percebo que o movimento gay está se redefinindo, a partir da aprovação do direito ao matrimônio gay. Aliás, há vários momentos no movimento gay espanhol. Primeiro foi a luta para descriminalizar a homossexualidade, que era, então, era na Espanha, um delito. Quando isso se resolve, e parece que todo mundo pode começar a manifestar-se, chega a AIDS. Quando a AIDS mais ou menos se cronifica, chega o casamento gay e uma pretensa normalização. Agora estamos nessa fase. A homofobia continua existindo, mas é uma homofobia mais sutil, mas ainda existe. Digamos, então, que, após a luta contra a criminalização da homossexualidade e luta contra a AIDS, o atual momento, o da homossexualidade pós-matrimonial, seria uma fase de redefinição dos objetivos do movimento.

\section{Referências}

ADIEGO, Jose Antonio Langarita. En tu árbol o en el mío: una aproximación etnográfica a la práctica del sexo anónimo entre hombres. Barcelona: Bellaterra, 2015.

BERGER, Peter L.; LUCKMANN, Thomas (1966). A construção social da realidade: tratado de sociologia do conhecimento. Petrópolis: Vozes, 1978.

BUTLER, Judith. Bodies that matter: on the discursive limits of "sex". New York \& London: Routledge, 1993.

Problemas de gênero: feminism e subversão da identidade. Rio de Janeiro: Civilização Brasileira, 2003.

De LAURETIS, Teresa. The practice of love: lesbian sexuality and perverse desire. Bloomington: Indiana UP, 1994.

DUARTE, Luiz Fernando Dias. A sexualidade nas ciências sociais: leitura crítica das convenções. In: PISCITELLI, Adriana; CARRARA, Sérgio; GREGORI, Maria Filomena (Orgs.). Sexualidade e saberes: convenções e fronteiras. Rio de Janeiro: Garamond, 2004.

FOUCAULT, Michel. História da sexualidade. A vontade de saber. v. 1. Rio de Janeiro: Graal, 1985.

FRY, Peter. Para inglês ver: identidade e política na cultura brasileira. Rio de Janeiro: Zahar, 1982.

GREEN, James. Além do carnaval: a homossexualidade masculina no Brasil do século XX. São Paulo: UNESP, 2000. 
GUASCH, Oìscar. De la "peineta" al "cuero": los homosexuales en la Catalunba actual. Tarragona: Universidad de Barcelona, Facultad de Filosofiìa y Letras, 1987.

El entendido: condiciones de aparicioìn, desarrollo y diso-lucioin de la subcultura homosexual en Espanha. Tarragona: Universidad de Barcelona, Facultad de Filosofiìa y Letras, 1991.

El modelo gay. In: GUASCH, Oscar. La sociedad rosa. 2.ed. Barcelona: Anagrama, 1995.

Observación participante. Barcelona: Centro de Investigaciones Sociologicas, 2002.

FOUCAULT, Michel. Em defesa da sociedade. São Paulo: Martins Fontes, 1999.

GUIMARÃES, Carmen Dora (1977). O homossexual visto por entendidos. Rio de Janeiro: Garamond 2004.

HEILBORN, Maria Luiza (Org.). Sexualidade: o olhar das ciências sociais. Rio de janeiro: Zahar, 1999.

KIMMEL, Michael S. A produção simultânea de masculinidades hegemônicas e subalternas. Horizontes Antropológicos, ano 4, n. 9. Porto Alegre: PPGAS, 1998.

MCRUER, Robert. Crip theory: cultural signs of queerness and disability. New York: New York University Press, 2006.

SANTOS, Boaventura de S. Um discurso sobre as ciências. São Paulo: Cortez, 2010.

WEEKS, Jeffrey. O corpo e a sexualidade. In: LOURO, Guacira Lopes. O corpo educado: pedagogias da sexualidade. Belo Horizonte: Autêntica, 1999. 